\title{
O mapa das parcerias público-privadas em saneamento no Brasil: uma análise comparada (2006-2017)
}

\author{
Demétrius Rodrigues de Freitas Ferreira \\ Universidade Federal de Pernambuco. Recife. Brasil \\ Email: demetriusrff@gmail.com
}

\author{
Anderson Henrique \\ Universidade Federal de Pernambuco. Recife, Brasil \\ Email: andersonheri@gmail.com
}

\begin{abstract}
Resumo:O processo de reforma estatal, associado a crise fiscal crônica, possibilitou novas formas de inserção do setor privado em áreas tradicionalmente sob a tutela do Estado. Recentemente, o Estado brasileiro está apostando emParcerias Público-Privadas (PPPs)para elevar o acesso ao serviço de esgotamento sanitário. $\mathrm{O}$ artigo se propõe a responder a seguinte questão: PPPs em esgotamento sanitário apresentam resultados melhoresem relação agestão pública dos serviços? O objetivo do presente artigo é analisar o comportamento dessas experiências em comparaçãocom casos de gestão pública dos serviços a partir dos indicadores de índice de atendimento total de esgoto e índice de esgoto tratado referido a água consumida. Metodologicamente, foi empregada estatística descritiva e teste T para amostras independentes entre os grupos. Os resultados indicam que não existe diferença substantiva na expansão dos serviços de esgotamento sanitário entre a gestão pública e as PPPs para os grupos analisados.
\end{abstract} pública.

Palavras-chave: Parcerias público-privadas, esgotamento sanitário, gestão

\section{Mapa de asociaciones público-privadas en saneamiento en Brasil: un análisis comparativo (2006-2017)}

Resumen: El proceso de reforma del Estado, asociado a la crisis fiscal de crisis, posibilitó nuevas formas de inserción del sector privado en áreas tradicionalmente bajo la tutela del Estado. Recientemente, el Estado brasileño está apostando en Asociaciones Público-Privadas (PPPs) para elevar o acceder al servicio Seúl. El articulo se propone responder a la siguiente situación: ¿Las PPPs en agotamiento tienen resultados positivos en relación a la gestión de servicios públicos? El objetivo del presente artículo es analizar el comportamiento de las experiencias en comparación con los casos de gestión pública, dos servicios basados ??en dos indicadores del índice de atención total del segmento e índice del segmento tratado referente al agua consumida. Metodológicamente, 
se implementó el T estadísticamente descriptivo y probado para casos independientes entre los grupos. Los resultados indican que no hay diferencia sustantiva en la expansión de dos servicios de saneamiento público entre gestión pública y PPPs para los grupos analizados. tión pública

Palabras clave: Asociaciones público-privadas, agotamiento sanitário, ges-

\title{
The map of public-private partnerships in sanitation in Brazil: a comparative analysis (2006-2017)
}

\begin{abstract}
The process of state reform, associated with the chronic fiscal crisis, has enabled new forms of insertion of the private sector in areas traditionally under state control. Recently, the Brazilian Department is betting on Public-Private Partnerships (PPPs) to increase access to sanitary sewage service. The paper proposes to answer the following question: do PPPs in sanitary sewage present better results in relation to the public management of services? The objective of the present article is to analyze the behavior of these experiences in comparison to the cases of public management of the services from the index of total service of sewage and treated sewage index referring to the water consumed. Methodologically, descriptive statistics and T-tests were used for independent samples between groups. The results indicate that there is no substantive difference in the expansion of sanitary sewage services between public management and PPPs in the analyzed groups.
\end{abstract}

Keywords: Public-private partnerships, sewage service, public management.

$* * *$

\section{Introdução}

Dentre as diversas definições existentes, o termo Parceria Público-Privada (PPP) pode ser definido como qualquer forma de relação entre o setor público e o privado que tenha por finalidade proporcionar bens e serviços para a sociedade (Bonomi e Malvessi, 2008). Esse modelo de cooperação tende a crescer vertiginosamente em função do deslocamento do papel do Estado como provedor de bens e serviços públicos.Neste sentido, o premente contexto de escassez de recursos em uma sociedade crescentemente globalizada e democrática, incentiva a associação de agentes públicos e privados para prover bem-estar à sociedade.

De modo a melhor definir o interesse deste trabalho, nosso objeto de análise está restrito ao conceito de PPP definido juridicamente pela Lei $\mathrm{n}^{\mathrm{o}}$ 11.079/2004 que ocorre sob duas diferentes modalidades de concessões públicas descritas no quadro 1, a seguir: 


\section{Quadro 1 - Modalidades de Concessões para PPP}

\begin{tabular}{|c|c|}
\hline $\begin{array}{l}\text { Patrocinada: é a concessão de um serviço } \\
\text { público (fundamentada nas Leis federais } \mathrm{n}^{\circ} \\
9.074 / 1995 \text { - Lei de Concessões e n }{ }^{\circ} 8.987 / 1995 \\
\text { - Lei de Licitações) que envolve a remuneração } \\
\text { do concessionário com base em tarifa cobrada dos } \\
\text { usuários e contraprestação do poder concedente. }\end{array}$ & $\begin{array}{l}\text { Administrativa: também se trata de uma } \\
\text { concessão de serviço público, porém não envolve } \\
\text { remuneração do concessionário via tarifa cobrada } \\
\text { dos usuários. Neste caso, o poder concedente arca } \\
\text { integralmente com a remuneração do } \\
\text { concessionário. }\end{array}$ \\
\hline
\end{tabular}

Fonte: Sundfeld (2005)

Juridicamente se trata de um gênero de concessão que se diferencia das formas tradicionais pelas seguintes características: seu contrato não pode ter valor inferior a 20 milhões de reais; o período de prestação dos serviços tem por tempo mínimo 5 anos e máximo de 35 anos; e a remuneração do parceiro privado poderá variar em função do desempenho do serviço prestado, conforme padrão de qualidade definido contratualmente.

O emprego de PPPs está associado a um amplo e histórico processo de reforma do Estado no sentido de modernizar a gestão pública, perseguindo formas mais flexíveis e eficientes face o quadro de crise fiscal crônica que limita a presença estatal em diversos setores de infraestrutura ou gestão de determinados serviços públicos. Tal processo busca dotar o Estado com maior racionalidade econômica através da incorporação de práticas gerenciais em suas funções ou simplesmente na sua redução em funções nas quais não representa uma alternativa eficiente. (Bresser, 2009;2011; Rezende, 2016).

Neste contexto, o setor de saneamento no Brasil expressa seus problemas de eficiência a partir do dilema entre a gestão privada e a pública, passando por períodos que oscilam por incentivos ora a privatização ora pela manutenção da gestão pública. Todavia, apesar do debate sobre o modelo de gestão mais eficiente no setor, os índices de atendimento a população com tais serviços ainda estãodistantes do aceitável. Segundo a base de dados do Sistema Nacional de Informação sobre Saneamento(SNIS) para o ano de 2015, mais de 35 milhões de brasileiros carecem de atendimento por água tratada e mais de 100 milhões não tem acesso aos serviços de coleta de esgotos, sendo expostos a condições de vida insalubres ${ }^{1}$.

Portanto, o emprego de PPPs expressa uma dentre várias estratégias para garantir maior racionalidade econômica na provisão de bens e serviços públicos, de modo a diminuir a pressão orçamentária para investimentos diretos em infraestrutura e aumentar a capacidade de ofertar benefícios sociais através de bens coletivos que, em tese, não podem ser ofertados pelo Estado em um período razoável de tempo. Entretanto, apesar de alargar a capacidade de investimento estatal, o seu uso também exerce pressão fiscal no orçamento público (Airoldi et 
al, 2013; Florizone e Carter, 2013), fazendo-se necessário pudor para equacionar a relação custo-benefício antes do emprego desta ferramenta.

Outra questão importante sobre o uso de PPPs na expansão dos serviços de saneamento envolve a polêmica sobre a natureza dos serviços. Por um lado, grupos empresariais ${ }^{2}$ advogam que o setor privado detém aexpertise para contribuir com a universalização dos serviços erepresentam uma alternativa imprescindível face a incapacidade estatal em arcar com os custos. Por outro lado, grupos refratários ${ }^{3}$ a participação privada na gestão do saneamento argumentam a incompatibilidade entre uma lógica empresarial de lucroe a necessidade de universalização dos serviços.

Para tanto, este artigo busca responder a seguinte questão: Parcerias Público-Privadas em esgotamento sanitário apresentam resultados melhores em relação a gestão pública dos serviços? O objetivo deste trabalho é verificar empiricamente se as experiências de PPPs apresentam resultados superioresa gestão pública (estadual ou municipal) quando comparados com casos selecionados em função da proximidade espacial e de semelhança populacional, social e econômica.

Portanto, o artigo foi dividido em quatro seções. Na primeira, apresenta-se um quadro geraldas experiências mapeadas no Brasil até o início de 2017. Posteriormente, descreve-se o procedimento metodológico adotado. Na terceira seção, apresenta-se os resultados empíricos obtidos a partir das experiências selecionadas. Por fim, na última seção, as conclusões.

\section{Características gerais das PPPs em saneamento no Brasil}

Desde 2006, ano da primeira PPP em saneamento no Brasil (Emissário Submarino de Jaguaribe em Salvador), até fevereiro de 2017 foram mapeadas 19 experiências no total, a partir do monitoramento de informações divulgadas na Caixa Econômica Federal (CEF), Banco Nacional de Desenvolvimento Econômico e Social (BNDES), Observatório das PPPs e oRadar PPP. Na figura 1 podemos observar a sistematização dessas experiências por Unidade Federativa (UF), ano e nome.

Como pode ser observado no mapa, figura 1, as PPPs estão distribuídas pelaRegião Sudeste, que concentra a maior quantidade, e pelaRegião Nordeste. Estas regiões concentram a maior parte da população brasileira, entretanto, diferente da Região Nordeste, o Sudesteé a que apresenta os melhores indicadores econômicos do Brasil, concentrando $55,4 \%$ do PIB nacional e possuindo a maior renda per capita(IBGE, 2010). De modo geral, a cobertura do serviço de coleta de esgotos no Brasil é de apenas 50,2\% e apresenta-se espacialmente concentrada na Região Sudeste, como pode ser observado na figura 2 . 


\section{Figura 1 - Mapa das PPPs em saneamento no Brasil}

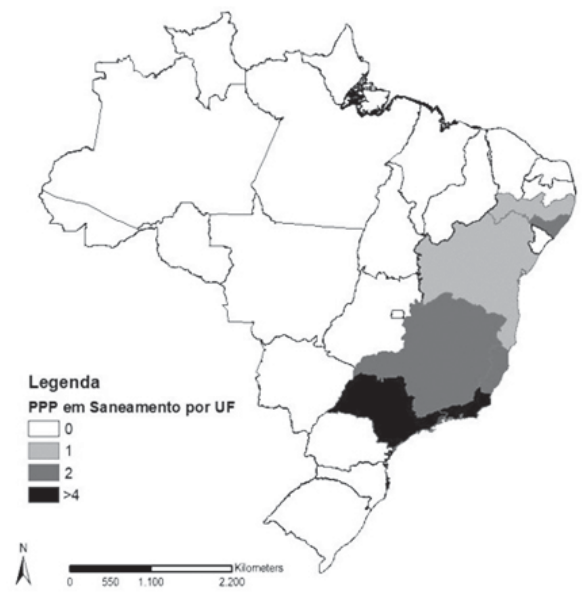

\begin{tabular}{|c|c|c|}
\hline Nome & UF & Ano \\
\hline Jaguaribe & BA & 2006 \\
\hline Rio Claro & SP & 2007 \\
\hline Rio das Ostras & RJ & 2007 \\
\hline Guaratinguetá & SP & 2008 \\
\hline Zona oeste AP 5 & RJ & 2011 \\
\hline Piracicaba & SP & 2012 \\
\hline Estancia de Atibaia & SP & 2012 \\
\hline Macae & RJ & 2012 \\
\hline PPP do Agreste & AL & 2012 \\
\hline Sistema São Lourenço & SP & 2013 \\
\hline Rio Manso & MG & 2013 \\
\hline $\begin{array}{c}\text { Região Metropolitana do } \\
\text { Recife }\end{array}$ & PE & 2013 \\
\hline Alto Tiete & SP & 2014 \\
\hline Guarulhos & SP & 2014 \\
\hline Paraty & RJ & 2014 \\
\hline Maceió & AL & 2014 \\
\hline Serra & ES & 2014 \\
\hline Divinópolis & MG & 2015 \\
\hline Vila Velha & ES & 2016 \\
\hline Fonte: Elaborado pelos autores (2017).
\end{tabular}

Fonte: Elaborado pelos autores (2017)

Figura 2

Taxa de cobertura dos serviços de esgotamento sanitário por UF e Distrito Federal em 2015

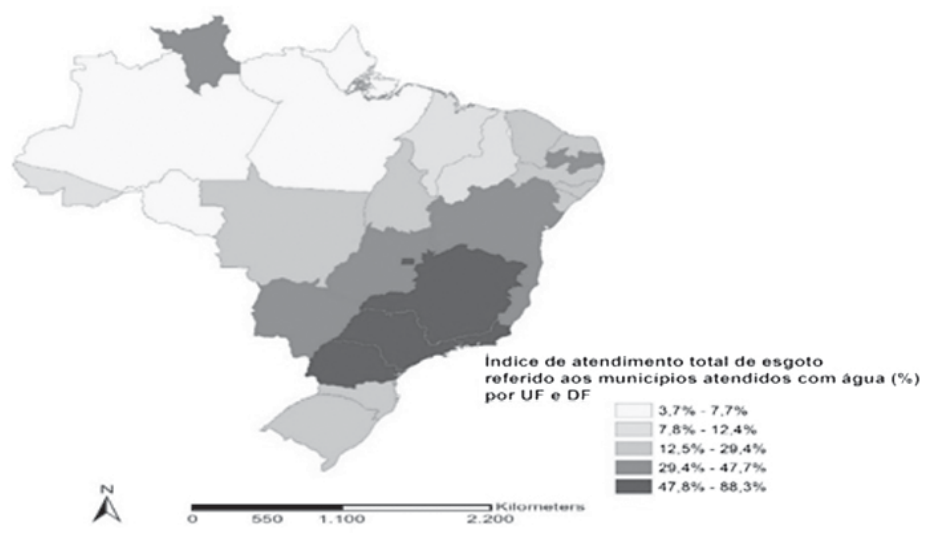

Fonte: Elaborado pelos autores (2017) 
Como é possível observar, o Brasil ainda não atingiu a universalização dos serviços de saneamento. Para o segmento de esgotamento sanitário, sua cobertura, a exceção da Região Sudeste, é inferior a 60\%, apresentando um quadro generalizado de baixa cobertura dos serviços. Todavia, como foi visto na Figura 1, a região que mais concentra experiência de PPPs é a mesma que mais próximo se encontra da universalização dos serviços.

O impacto da baixa cobertura dos serviços apresenta reflexo direto na qualidade de vida da população. Somente no ano de 2011, estima-se que 396.048 mil pessoas foram internadas por diarreia no Brasil e desse total 35\% (138.447) foram crianças menores de 5 anos (Kronembergere Clevelário Junior, 2013). Além da saúde, a ausência deste serviço também tem reflexos negativos, porém de difícil mensuração, para o meio ambiente, turismo, educação e trabalho.

Em função do baixo nível de cobertura e da demanda volumosa por investimentos para alcançar a universalização, foi lançado o Plano de Parcerias Público-Privada (PLP) no início de 2015 (Decreto nº 8.428), durante o governo da presidenta Dilma Russeff com o objetivo de atrair investimentos privados em diversos setores de infraestrutura, inclusive saneamento. O PLP consistia em facilitar a tomada de crédito por parte dos investidores a juros baixos para investimentos em áreas consideradas estratégicas pelo governo, bem como a transferência de áreas "não essenciais”, a exemplo dos aeroportos para o setor privado. O PLP foi considerado tímido em termos de atratividade financeira para o setor privado.

Os 19 contratos de PPPs em curso no Brasil representam, segundo alguns analistas (Pereiraet al., 2016), uma pequena parcela do potencial de capitalização no setor. A soma total dos investimentos atual, em saneamento a partir de PPPs,é estimada em torno de 15 bilhões de reais, porém, de acordo com os autores, poderia atingir patamares de investimentos superiores.

O mercado de PPPs no Brasil, apesar de ser descrito como potencialmente amplo, é caracterizado pela presença marcante de poucas empreiteiras como detentoras da maior parte das concessões. Até o final de 2016, apenas duas empreiteiras detinham mais da metade das concessões. No gráfico1 abaixo, apresenta-se por percentual a participação de empreiteiras e grupos que atuam no segmento de PPPs em saneamento no Brasil. 


\section{Gráfico 1. \\ Distribuição de PPPS em saneamento por parceiros privados no brasil (2016)}

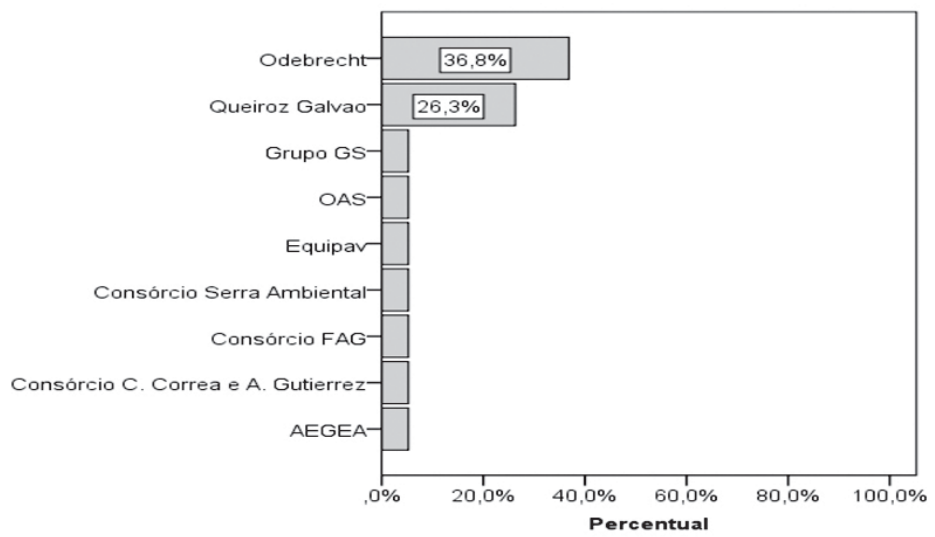

Fonte: Elaborado pelos autores (2017).

Como pode ser visto acima, somente a Odebrecht ${ }^{4}$ detém 36,8\% deste mercado que, somado a parcela do grupo Queiroz Galvão (26,3\%), totalizam o domínio de 63,1\%. Esse quadro caracteriza o oligopólio destas duas empresas no setor ${ }^{5}$.

Após um conturbado processo político que culminou no impeachment da então presidenta Dilma Russeff, em 2016, o presidente Michel Temer em seu primeiro dia de governo substituiu o PLP pelo Programa de Parceria para Investimentos (PPI, 2016), com um claro viés de desestatização ${ }^{6}$ da infraestrutura e diversos serviços públicos, incluindo os de saneamento, sob o pretexto da retomada de investimentos para "acelerar o crescimento" nacional. A lei que criou o PPI, Lei n ${ }^{\circ} 13.334 / 2016$, reservou ao Banco Nacional de Desenvolvimento Social (BNDES), outrora utilizado como banco fomentador da infraestrutura nacional, como agente responsável pelo Fundo de Apoio à Estruturação das Parcerias (FAESP) para tratar da modelagem e estruturação de parcerias para desestatização da infraestrutura, com atenção especial ao setor de saneamento.

No início de 2017, foi anunciado o Programa de Concessões de Saneamento do governo federal, incentivando estados e municípios a aderir ao programa que inicialmente vai implantar estudos com consultorias especializadas para definir o melhor modelo de parceria com o setor privado para concessão dos serviços de saneamento ${ }^{7}$. Ao todo, oito estados aderiram ao programa até o início de 2017 e dez demonstraram interesse em participar, indicando que o PPI pode resultar em um largo processo de privatização 
dos serviços em um curto espaço de tempo, com previsão de lançar as licitações no início de 2018.

\section{Procedimentos metodológicos}

Até o início de2017, foram mapeadas 19 experiências que estão distribuídas entre os setores de abastecimento de água, abastecimento e esgotamento sanitário e apenas esgotamento sanitário. Na Tabela 1 abaixo é possível observara frequência dos casos por setor.

\section{Tabela 1}

\section{Casos de PPP em saneamento por setor}

\begin{tabular}{|l|c|c|}
\hline \multicolumn{1}{|c|}{ PPP por setor } & Frequência & Percentual \\
\hline Abastecimento de água & 4 & 22,2 \\
\hline $\begin{array}{l}\text { Abastecimento de água e esgotamento } \\
\text { sanitário }\end{array}$ & 2 & 11,1 \\
\hline Esgotamento sanitário & 13 & 66,7 \\
\hline \multicolumn{1}{|c|}{ Total } & 19 & 100,0 \\
\hline
\end{tabular}

Fonte: Elaborado pelo autor(2017)

Em função da baixa cobertura generalizada do esgotamento sanitário e do grande passivo social que este representa, optou-se por analisar apenas esse segmento. Dos casos observados, foram excluídos aqueles que não satisfaziam o nosso recorte inicial. Como a base de dados disponível pelo SNIS somente dispõe de dados até o ano de 2015, selecionou-se apenas experiências com um mínimo de 4 anos (2012-2015) em curso, prazo referente a uma gestão governamental, para verificar com mais segurança os resultados das PPPs adotadas. Desse modo, das 13 experiências existentes, excluiu-senovecasos dos quais seis em função do ano de início da PPP (após o ano de 2012) e mais três casos: um na Bahia, uma PPP para construção de emissário submarino que não reflete diretamente no aumento da cobertura do serviço e outros dois no Rio de Janeiro, a Zona Oeste AP 5 e Rio das Ostras, por falta de informações precisas.

Como restaram apenas quatro casos, optou-se por fazer um estudo comparativo entres as experiências municipais de PPPs em esgotamento sanitário com casos de municípios circunvizinhos de perfil socioeconômico aproximado e com gestão pública do serviço. Para tanto, dividiu-se a amostra em dois grupos, como pode ser observado na Tabela 2, 
Tabela 2.

\section{Perfil socioeconômico dos municípios analisados}

\begin{tabular}{|c|c|c|c|c|}
\hline & Casos & $\begin{array}{l}\text { Populaçào total } \\
\text { estimada (2016) }\end{array}$ & $\begin{array}{l}\text { IDHM } \\
(2010)\end{array}$ & $\begin{array}{l}\text { Renda per } \\
\text { capita }(2010)\end{array}$ \\
\hline \multirow{4}{*}{ 递㝕 } & Piracicaba(SP) & 394.419 & 0,785 & $1.143,20$ \\
\hline & Guaratinguetá(SP) & 119.753 & 0,798 & 926,78 \\
\hline & Atibaia (SP) & 138.449 & 0,765 & $1.063,52$ \\
\hline & Rio Claro (SP) & 201.473 & 0,803 & $1.049,16$ \\
\hline \multirow{4}{*}{ 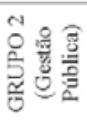 } & Santa Bárbara D'Oeste & 191.024 & 0,781 & 863,02 \\
\hline & Pindamonhangaba & 162.327 & 0,773 & 826,02 \\
\hline & Franco da Rocha & 147.650 & 0,731 & 632,42 \\
\hline & Araras (SP) & 130.102 & 0,781 & 921,76 \\
\hline
\end{tabular}

Fonte: Elaboração dos autores (2017), com base no IBGE(2010) e PNUD (2013).

O grupo 1 concentra as experiências de PPPs e o grupo 2 as de gestão pública. Os municípios do grupo 2 foram selecionados pelo critério de maior semelhança do tamanho populacional, do Índice de Desenvolvimento Humano Municipal (IDHM) e da renda per capita associados ao critério de proximidade espacial. $\mathrm{Na}$ amostra, todos os municípios são categorizados como de grande porte segundo faixa populacional ( $>100.000$ mil habitantes), com IDHM situado nas faixas alto $(>0,7)$ e muito alto $(>0,8)$ e com renda média per capita superior amédia nacional $\left(793,87 \mathrm{R} \$^{8}\right)$, apenas com a exceção do município de Franco da Rocha que apresenta uma renda per capita inferior à média nacional e a todos os casos analisados. Na Figura 3, abaixo, apresenta-se a localização espacial dos casos, no estado de São Paulo.

Figura 3

\section{Mapa dos casos analisados no estado de São Paulo}

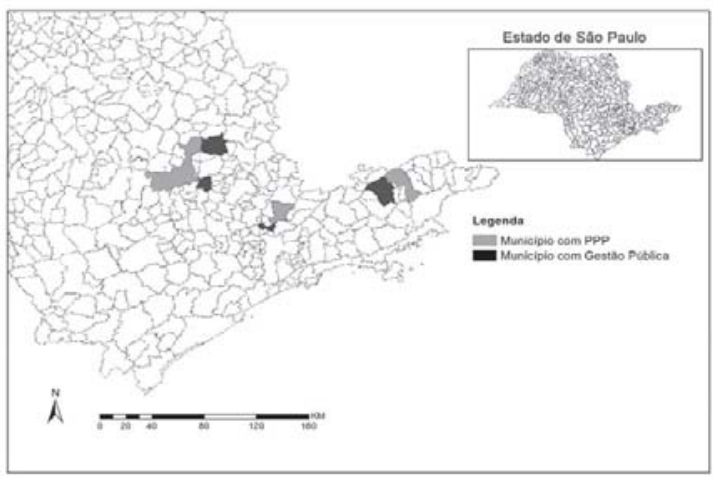

Fonte: Elaboração dos autores (2017). 
Como o nosso objetivo é fazer um estudo comparativo entre os casos do grupo 1 e 2 para verificar como se comportam as experiências de PPPs em relação aos casos de gestão pública, optou-se por fazer uma comparação por pares durante o período inicial da década de 2000 até 2015, com base nos indicadoresapresentados no Quadro 2.

\section{Quadro 2}

\section{Descrição dos indicadores utilizados para comparação entre os casos}

\begin{tabular}{|l|l|c|}
\hline \multicolumn{1}{|c|}{ Variável } & \multicolumn{1}{|c|}{ Mensuração } & \multicolumn{1}{c|}{$\begin{array}{c}\text { Código no } \\
\text { SNIS }\end{array}$} \\
\hline $\begin{array}{l}\text { Índice de atendimento total de esgoto } \\
\text { referido aos municípios }\end{array}$ & $\begin{array}{l}\text { Mede o acesso da população ao serviço } \\
\text { de coleta de esgoto }\end{array}$ & IN46 \\
\hline $\begin{array}{l}\text { Índice de esgoto tratado referido a água } \\
\text { consumida }\end{array}$ & $\begin{array}{l}\text { Mede o percentual de esgoto tratado } \\
\text { referente a água consumida }\end{array}$ & IN56 \\
\hline
\end{tabular}

Fonte: Elaborado pelos autores (2017).

Posteriormente foi realizado um teste $\mathrm{T}$ para amostras independentes visando verificar se existe diferença significativa na média de expansão dos serviços durante o período de implantação das PPPs. Vale ressaltar que cada contrato de PPP tem prazos e metas próprios, que não estão sendo considerados aqui por razões metodológicas, pois o nosso objetivo é verificar como se comportam as experiências de PPP em relação aos casos de gestão pública com características socioeconômicas similares e espacialmente próximos ao longo dos anos. A análise dos dados e a criação dos mapas foram elaboradas com o auxílio dos softwaresStatistical Package for Social Science(SPSS), versão 22, e ArcGis, versão 10.3, respectivamente. Por último, para fins de replicação por parte da comunidade científica, os dados analisados e os arquivos dos mapas encontram-sepúblicos no repositório de dados do $\mathrm{OsF}^{9}$.

\section{Análise comparada entre os casos de PPPs e de gestão pública}

Iniciando pelo caso de Piracicaba, em 2012, o município assinou um contrato de concessão administrativa com prazo de 30 anos com o propósito de universalizar a coleta e o tratamento de esgotos. Para fins de comparação, selecionou-se o município de Santa Bárbara D’Oeste, com localização limítrofea sudeste de Piracicaba e que mantém a gestão municipal na coleta e tratamento do esgoto. No gráfico 2, abaixo, pode-se observar a variação que houve entre os dois casos na coleta e no tratamento de esgotos, com destaque para o período de implantação da PPP em Piracicaba. 


\section{Gráfico 2}

Variação do índice de coleta e tratamento de esgotos no período de 2000 a 2015 entre os municípios de Piracicaba e Santa Bárbara D’Oeste
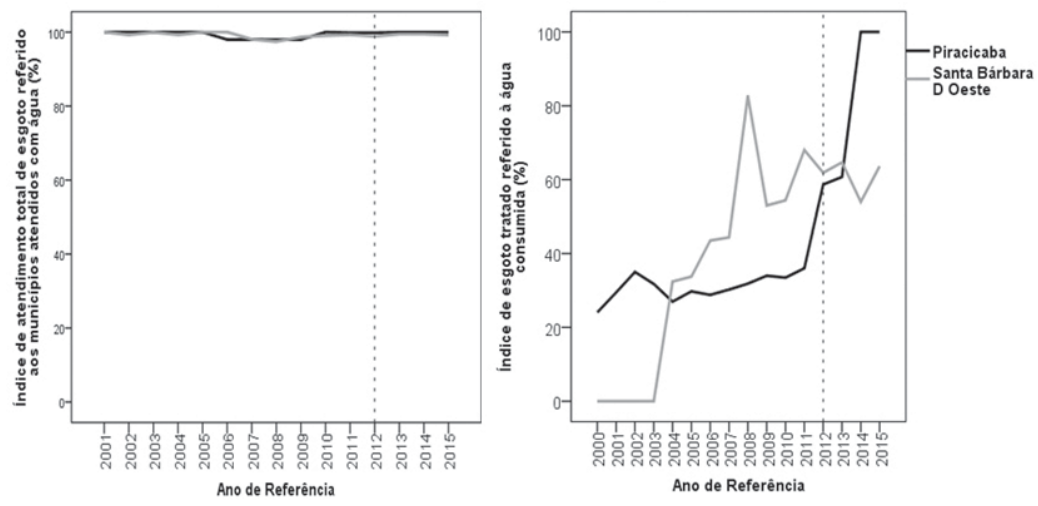

Fonte: Elaborado pelos autores (2017) a partir do SNIS (2015).

Como é possível observar, em 2001 ambos os casos já apresentavam $100 \%$ de atendimento com coleta de esgoto que no decorrer dos anos variou, apresentando uma retração entre os anos de 2005 (Piracicaba) e 2006 (Santa Bárbara D’Oeste). Em 2011, ainda sob gestão pública municipal, Piracicaba retomou o patamar de atendimento inicial e em 2012 concedeu o serviço em regime de PPP para a empresa Equipav,mantendo o índice de coleta de esgotos em 100\% até o ano de 2015 ao passo que o município de Santa Bárbara D’Oeste apresentou um comportamento similar, atingindo um índice de 99\% de coleta de esgotos em 2015.

Quanto ao índice de tratamento de esgoto coletado, observou-se que ambos os casos apresentaram expansão do serviço no decorrer dos anos, com destaque para o município de Piracicaba que teve tendência de crescimento desde 2001 e em 2012 (ano de assinatura do contrato de PPP) manteve o desempenho e atingiu 100\% do esgoto tratado referido a água consumida ainda em 2014. Por sua vez, o município de Santa Bárbara D’Oeste também apresentou tendência de expansão do serviço no período observado, atingindo 60\% de esgoto tratado referido a água consumida em 2015.

De forma geral, é possível observar que os casos observados iniciam a década de 2000 com taxas similares de oferta dos serviços e no decorrer dos anos apresentaram tendências semelhantes, com resultados similares quanto a coleta de esgoto. No que se refere ao tratamento do esgoto coletado, verifica-se que ambos os casos apresentaram um comportamento de expansão ao longo dos anos, com destaque para o ano de 2012 em que o município de Piracicaba assinou o contrato de PPP e manteve a tendência 
de crescimento na oferta do serviço até alcançar a universalização em 2014 ao passo que em Santa Bárbara D’Oeste, desde 2008, não conseguiu manter a tendência de expansão, atingindo o patamar de $60 \%$ de tratamento do esgoto coletado em 2015.

Analisando o caso de Guaratinguetá, em 2008, o município assinou um contrato de concessão administrativa com prazo de 30 anos com o propósito de universalizar a coleta e o tratamento de esgotos. Para fins de comparação, selecionou-se o município de Pindamonhangaba, com localização limítrofe a oeste de Guaratinguetá e que mantém a gestão pública na coleta e tratamento do esgoto operado pela empresa estadual Companhia de Saneamento Básico do Estado de São Paulo (SABESP). Como pode-se observar no Gráfico 3, houve variação entre os dois casos na coleta e no tratamento de esgotos, com destaque para o período de implantação da PPP.

\section{Gráfico 3 \\ Variação do índice de coleta e tratamento de esgotos no período de 2000 a 2015 entre os municípios de Guaratinguetá e Pindamonhangaba}

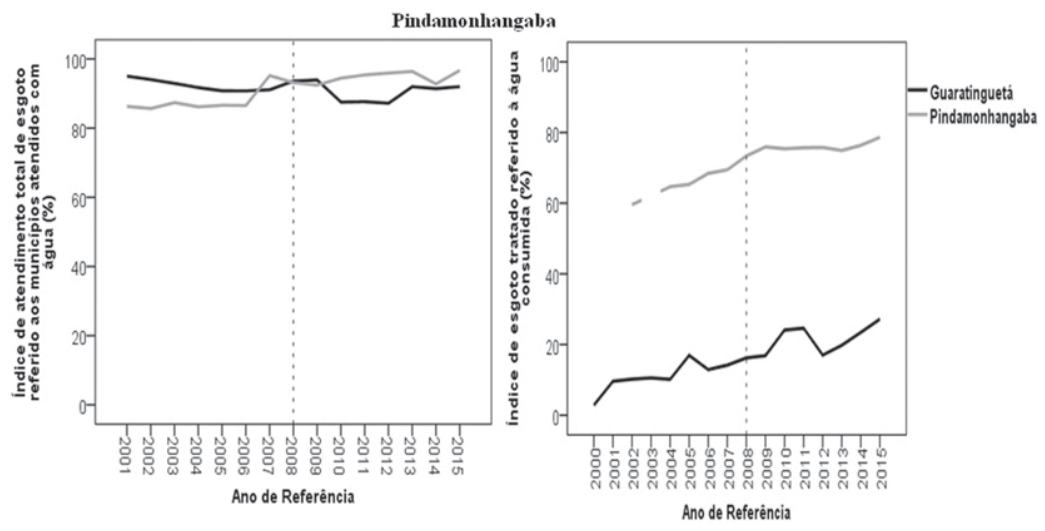

Fonte: Elaborado pelos autores (2017) a partir do SNIS (2015).

Quanto ao índice de coleta de esgoto, é possível observar tendências diferentes para os casos observados. Em Pindamonhangaba, verifica-se a tendência de expansão do serviço ao longo dos anos, ampliando em 10\% o índice de coleta de esgoto no período 2001-2015. Por sua vez, em Guaratingetá, a tendência observada foi de retração no qual desde 2001 até 2008 (ano de assinatura do contrato de PPP) o município reduziu a oferta do serviço e após 2008 manteve a tendência de redução em relação ao patamar de 2001. Quanto ao índice de esgoto tratado referido a água consumida,ambos os casos apresentaram tendências semelhantes na 
expansão do serviço de tratamento de esgoto, tendo Pindamonhangaba incrementado em 20\% e Guaratingetá em 24,4\% no período de 2000 até 2015.

A experiência de PPP em Guaratingetá (2008) mostrou-se incapaz em reverter a tendência de retração do serviço de coleta de esgoto no período analisado, bem como apresentou resultados similares ao município de Pindamonhagaba na expansão do índice de esgoto tratado referido por água consumida. Ademais, Pindamonhagaba apresentou tendência crescente tanto para a coleta quanto para o tratamento de esgoto ao longo do período analisado.

Em relação àAtibaia, em 2012, o município assinou um contrato de concessão administrativa com prazo de 30 anos com o propósito de universalizar a coleta e o tratamento de esgotos. Para fins de comparação, selecionou-se o município de Franco da Rocha, com localização limítrofe ao sul de Atibaia e que mantém a gestão pública na coleta e tratamento do esgoto operado pela SABESP. Como é possível observarno Gráfico 4, ambos os casos apresentam tendências distintas de expansão do índice de coleta e tratamento de esgoto ao longo do tempo.

\section{Gráfico 4 \\ Variação do índice de coleta e tratamento de esgotos no período de 2000 a 2015 entre os municípios de Atibaia e Franco da Rocha}
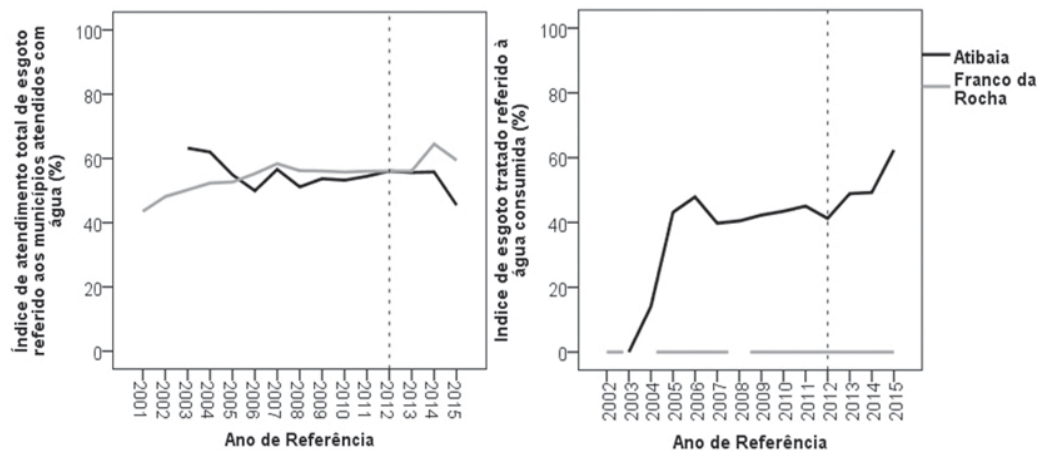

Fonte: Elaborado pelos autores (2017) a partir do SNIS (2015).

Referente ao índice de coleta de esgoto, o município de Atibaia apresentou uma tendência de retração do serviço ao longo do tempo, com destaque para o período de implantação da PPP que agravou a tendência de retração. Já o município de Franco da Rocha seguiu uma tendência oposta, incrementando o acesso ao serviço em cerca de $20 \%$ no período observado (2001-2015). Em relação ao outro índice, a partir de 2003, Atibaia apresentou 
um forte crescimento, principalmente em 2012 com a PPP, mantendo a tendência de ampliar o tratamento do esgoto municipal enquanto em Franco da Rocha, de acordo com a base de dados do SNIS no período observado, ainda não dispõe do serviço de tratamento de esgoto.

O município de Rio Claro, em 2007, assinou um contrato de concessão administrativa com prazo de 30 anos com o propósito de universalizar a coleta e o tratamento de esgotos. Para fins de comparação, selecionou-se o município de Araras, com localização limítrofe à leste de Rio Claro e que mantém a gestão pública municipal na coleta e tratamento do esgoto. Como é possível observar no Gráfico 5, ambos os casos apresentam tendências semelhantes de expansão do índice de coleta e tratamento de esgoto ao longo do tempo.

\section{Gráfico 5 \\ Variação do índice de coleta e tratamento de esgotos no período de 2000 a 2015 entre os municípios de Araras e Rio Claro}
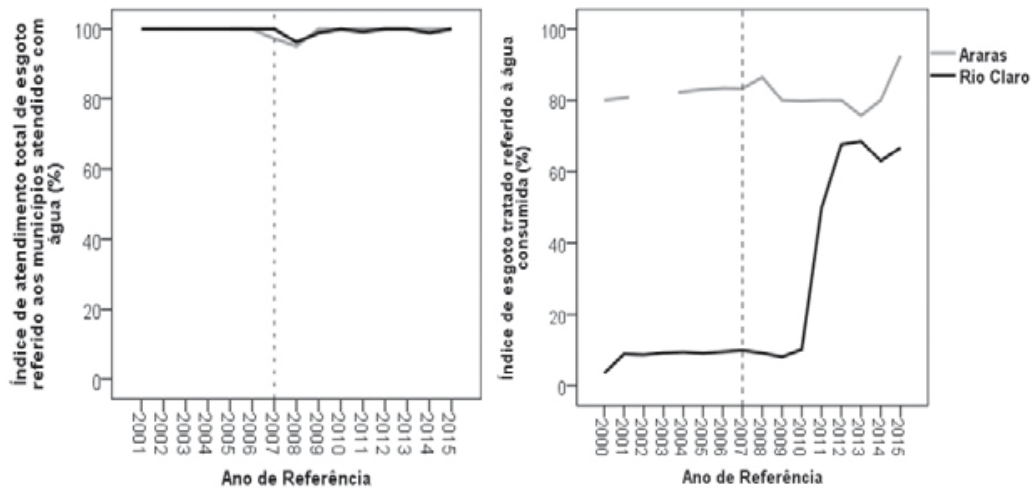

Fonte: Elaborado pelos autores (2017), a partir do SNIS (2015)

Ambos os casos apresentam comportamento semelhante quanto a variação no índice de coleta de esgoto, bem como lograram manter a universalização do serviço. Quanto ao índice de tratamento de esgoto, verifica-se que após 2007 (ano de assinatura do contrato de PPP) o município de Rio Claro apresentou um crescimento vertiginoso, saltando de uma taxa de $9,8 \%$ para $66,7 \%$ de tratamento do esgoto coletado, ao passo que o município de Araras apresentou um incremento modesto, crescendo apenas 9\% no período observado (2000-2015).

De acordo com os dados apresentados, a variação no índice de coleta de esgoto foi similar para ambos os casos, porém, quanto ao índice de 
tratamento de esgoto, o município de Rio Claro apresentou um forte crescimento, mas, o município de Araras, mesmo com um crescimento modesto apresentou um índice de tratamento de esgoto de 93\%.

De modo geral, a partir dos casos comparados, não foi possível identificar uma tendência clara para responder a nossa questão de pesquisa. Para tanto, empregou-se um teste $\mathrm{T}$ para amostras independentes para verificar se existe diferença média entre os grupos para os índices de coleta e tratamento de esgoto. Na tabela 3, abaixo, apresenta-se a estatística descritiva referente a quantidade de casos analisados por grupo (referente apenas aos casos por ano pós implantação da PPP), a média dos índices analisados por grupo e o desvio padrão.

\section{Tabela 3}

\section{Estatística descritiva por grupo}

\begin{tabular}{c|c|c|c|c}
\hline Indicador & Grupo & Casos & Média & $\begin{array}{c}\text { Desvio } \\
\text { Padrão }\end{array}$ \\
\hline \multirow{2}{*}{$\begin{array}{c}\text { Índice de atendimento total de esgoto referido aos } \\
\text { municípios atendidos com água }\end{array}$} & PPP & 30 & 90,8 & 15,6 \\
\cline { 2 - 5 } & $\begin{array}{c}\text { Gestão } \\
\text { Pública }\end{array}$ & 30 & 92,5 & 13,6 \\
\hline \multirow{2}{*}{ Índice de esgoto tratado referido à água consumida } & PPP & 30 & 40,3 & 25,3 \\
\cline { 2 - 5 } & $\begin{array}{c}\text { Gestão } \\
\text { Pública }\end{array}$ & 30 & 63 & 27,3 \\
\hline
\end{tabular}

Fonte: Elaboração dos autores (2017).

Para o Índice de atendimento total de esgoto referido aos municípios atendidos com água, o testt para amostras independentes mostrou que não existe diferença significativa entre o grupo PPP e o grupo gestão pública $(\mathrm{t}(58)=-3,34 ; \mathrm{p}$-valor= 0,661$)$. Por sua vez, para Índice de esgoto tratado referido à água consumida, observou-se que os casos do grupo PPP, em média, apresentam uma taxa de 22,72\% inferior ao grupo gestão pública $(\mathrm{t}(58)=-0,441 ; \mathrm{p}-\mathrm{valor}=0,001)$.

\section{Conclusão}

Este trabalho elaborou o mapa das PPPs em saneamento no Brasil e apresentou empiricamente os resultados das experiências em curso, com o objetivo de verificar se houve expansão dos serviços ou não em comparação com casos de municípios circunvizinhos que mantiveram a gestão pública dos serviços. Os resultados obtidos são inconclusivos no sentido de afirmar se o modelo de PPP na gestão do serviço de esgotamento sanitário é superior ou inferior ao modelo de gestão pública estadual ou municipal, todavia, é possível afirmar que as experiências de PPPs com mais de 4 anos 
em curso não apresentam resultados melhores do que a gestão pública dos serviços.

As experiências de PPPs apresentam tendências diferentes nos casos analisados. Apenas para o caso de Piracicaba se observou uma tendência crescente de expansão da coleta e tratamento do esgoto, ao passo que para os casos de Atibaia e Rio Claro se verificou uma maior expansão na taxa de tratamento de esgoto. Por sua vez, no caso de Guaratinguetá e Atibaia, observou-se uma tendência de retratação na taxa de coleta de esgoto.

Em comparação com os municípios de gestão pública, os casos de Pindamonhangaba e Araras apresentaram expansão da taxa de coleta e tratamento de esgoto superior aos municípios analisados que adotaram PPPs para universalização dos mesmos.

Apesar dos esforços do governo federal em incentivar a adoção de PPPs, empiricamente, verificou-se que as experiências em curso não correspondem as expectativas políticas de expansão dos serviços, nem justificam a formulação de planos ousados para difundir a adoção irrestrita de parcerias com a iniciativa privada, como vem acontecendo. Mesmo que não seja possível inferir conclusões robustas a partir da amostra analisada, os resultados obtidos sugerem que tais parcerias não apresentam a propalada capacidade para alavancar a infraestrutura de coleta e tratamento de esgotos no Brasil. É com muita cautela que é feita essa afirmação, pois se trata de um processo ainda recente e com poucos casos, mas os resultados do desempenho do setor privado via PPPs,até o momento, indicam que tais experiências passam ao largo da pretendida universalização.

Se a justificativa para a adoção de PPPs está associada a "ineficiência” estatal em universalizar os serviços, tampouco o setor privado apresenta evidências empíricas para cobrir a alternativa estatal.

Ao fim, o objetivo deste trabalho é contribuir com o debate sobre a melhor solução para alcançar a universalização do saneamento no Brasil e, sobretudo, apresentar evidências empíricas para a melhor tomada de decisões públicas.

\section{Agradecimentos}

Agradecemos ao grupo de pesquisa Métodos de Pesquisa em Ciência Política (MPCP) do Departamento de Ciência Política da Universidade Federal de Pernambuco (DCP/UFPE), aos professores Dr. Dalson Figueiredo Filho e Dr. Enivaldo Rocha e aos pareceristas da Revista Polis por suas contribuições fundamentais na construção deste artigo. 


\section{Notas}

${ }^{1}$ A falta de saneamento expõe a população a diferentes tipos de riscos, dos quais destacamos como o principal o risco à saúde através da exposição a diversas doenças como a leptospirose, amebíase, esquistossomose e de verminose que podem levar a óbito (para maiores informações, consultar os informes do Instituto Trata Brasil em http://www.tratabrasil.org.br ).

${ }^{2}$ A exemplo da Associação Brasileira das Concessionárias Privadas dos Serviços Públicos de Água e Esgotos (AESB) que congrega mais de 60 empresas que atuam no ramo do saneamento e defende a maior participação privada na gestão dos serviços.

${ }^{3}$ A Frente Nacional Pelo Saneamento Ambiental (FNSA) é um exemplo dos grupos refratários a inserção privada no saneamento, congregando sindicatos, associações de classe, Organizações Não Governamentais (ONGs) e movimentos sociais diversos. Para maiores informações, consultar: http://saneamentoparatodos.blogspot.com.br/

${ }^{4}$ Ao final de 2016, a Odebrecht vendeu cerca de 70\% da Odebrecht Ambiental, empresa subsidiária responsável pelas concessões em saneamento no Brasil para a gestora de fundos canadense Brookfield como forma de alavancar recursos para pagar acordo de leniência firmado com o Ministério Público Federal.

${ }^{5}$ As empreiteiras Odebrecht, Queiroz Galvão, Andrade Gutierrez e Camargo Corrêa estão envolvidas em uma variedade crimes revelados pela Operação Lava Jato que desbaratou um amplo esquema de corrupção envolvendo a captura sistemática do Estado por meio do financiamento de campanhas políticas para a maioria dos partidos políticos com o objetivo de favorecimento empresarial em obras e concessões públicas.

${ }^{6}$ http://www2.planalto.gov.br/acompanhe-planalto/noticias/2016/09/entenda-o-programa-de-parcerias-de-investimentos[Acessado em 3 de Maio de 2017].

${ }^{7}$ http://www.saneamentobasico.com.br/portal/index.php/concessoes/programa-deparcerias-para-investimentos-ppi-do-saneamento-so-em-2018/[Acessado em 3 de Maio de 2017].

${ }^{8}$ A renda média per capita nacional é referente ao ano de 2010 (IBGE, 2010).

${ }^{9}$ Para acesso aos arquivos do banco de dados e demais itens dos mapas, favor acessar: https://osf.io/pfxuy/ [Acessado em 1 de junho de 2018]. 


\section{Bibliografía}

Airoldi, M,et al.(2013). Meeting the Infrastructure Challenge with PublicPrivate Partnerships: Bridging the Gap. Boston, Estados Unidos: The Boston Consulting Group.

Bonomi, C. A., Malvessi, O. (2008). Project Finance no Brasil: Fundamentos e Estudo de Caso. São Paulo, Brasil: Editora Atlas.

Decreto $n^{0} 8.428$, de 02 de abril de 2015. Dispõe sobre o procedimento de manifestação de interesse a ser observado na apresentação de projetos, levantamentos, investigações ou estudos, por pessoa física ou jurídica de direito privado, a serem utilizados pela administração pública.Recuperado de http://www.planalto.gov.br/ccivil_03/ _ato2015-2018/2015/decreto/d8428.htm.

Lei $\mathrm{n}^{0}$ 13.334, de 13 de setembro de 2016. Cria O Programa de Parcerias de Investimentos - PPI; Altera A Lei No 10.683, de 28 de Maio de 2003, e Dá Outras Providências.Recuperado de http://www.planalto.gov.br/ ccivil_03/_ato2015-2018/2016/lei/L13334.htm

Bresser Pereira, L. C. (2009) Construindo o Estado republicano.Rio de Janeiro, Brasil: FGV.

(2011). Reforma do estado para a cidadania: a reforma gerencial brasileira na perspectiva internacional. Rio de Janeiro, Brasil: Editora 34.

Florizone, R. y Carter, L (2013). Smart Lessons, A winning Framework for Public-Private Partnerships: Lessons from 60-Plus IFC projects. Washington DC, Estados Unidos: World Bank.

Instituto Brasileiro de Geografia e Estatística - IBGE. (2010). Censo Demográfico - 2010. Rio de Janeiro, Brasil: IBGE.

Kronemberger, D. y Clevelário Junior, J (2013). Esgotamento Sanitário Inadequado e Impactos na Saúde da População.São Paulo, Brasil:Instituto Trata Brasil.

Pereira, B. et al (2016). PPP Summit 2016:rumo aos 100 contratos. São Paulo, Brasil: RADAR PPP.

Programa das Nações Unidas para o Desenvolvimento (PNUD). Atlas do desenvolvimento humano no Brasil. Recuperado de: http:// www.pnud.org.br/atlas/.acesso

Rezende, F (2016). Os leviatãs estão fora do lugar.Recife, Brasil: Editora UFPE. 
Sistema Nacional de Informações Sobre Saneamento - SNIS (2015). Diagnóstico dos serviços de água e esgotos. Recuperado de: http://www. snis.gov.br/.

Sundfeld, C (2005). Guia jurídico das parcerias público-privadas. En Sundfeld, C (Ed.) Parcerias público-privadas. São Paulo, Brasil: Malheiros Editores.

Recibido: 19.09 .17

Aceptado: 20.06.18 